\title{
DDPWM-based power conversion system using three to four phase matrix converter for stand-alone power system
}

\begin{abstract}
This paper presents a novel stand-alone power system using a three to four phase matrix converter (MC) for use with renewable energy sources such as a micro hydro turbine or a tiny wind turbine with a permanent magnet synchronous generator (PMSG). MCs are able to convert $\mathrm{AC}$ power to $\mathrm{AC}$ power directly without using $\mathrm{DC}$ link capacitors, and $\mathrm{AC}$ to $\mathrm{DC}$ conversion is also possible because DC is considered to be a type of AC power. Here, two single phase AC outputs with constant frequency and two DC outputs for a battery storage system are described for a fluctuating voltage source. Direct duty ratio pulse width modulation (DDPWM) is used to achieve the desired output because it is easy to expand an ordinary three to three phase MC to produce a three to four phase MC. In addition, fictitious reference iterative tuning (FRIT) is used to design the controller gains. The validity of the proposed method is demonstrated using MATLAB/Simulink simulations.
\end{abstract}

Keyword: Direct duty ratio pulse width modulation; Fictitious reference iterative tuning; Stand-alone power system; Three to four phase matrix converter 